\title{
A Decision Support System for Dynamic Job-Shop Scheduling Using Real-Time Data with Simulation
}

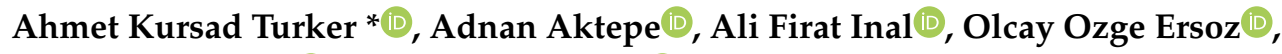

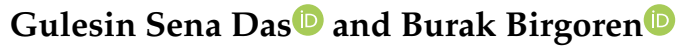 \\ Department of Industrial Engineering, Kirikkkale University, 71451 Campus, Turkey; aaktepe@kku.edu.tr (A.A.); \\ afinal@kku.edu.tr (A.F.I.); ooersoz@hotmail.com (O.O.E.); senadas@kku.edu.tr (G.S.D.); \\ birgoren@kku.edu.tr (B.B.) \\ * Correspondence: kturker@kku.edu.tr
}

Received: 26 February 2019; Accepted: 14 March 2019; Published: 19 March 2019

check for updates

\begin{abstract}
The wide usage of information technologies in production has led to the Fourth Industrial Revolution, which has enabled real data collection from production tools that are capable of communicating with each other through the Internet of Things (IoT). Real time data improves production control especially in dynamic production environments. This study proposes a decision support system (DSS) designed to increase the performance of dispatching rules in dynamic scheduling using real time data, hence an increase in the overall performance of the job-shop. The DSS can work with all dispatching rules. To analyze its effects, it is run with popular dispatching rules selected from the literature on a simulation model created in Arena ${ }^{\circledR}$. When the number of jobs waiting in the queue of any workstation in the job-shop falls to a critical value, the DSS can change the order of schedules in its preceding workstations to feed the workstation as soon as possible. For this purpose, it first determines the jobs in the preceding workstations to be sent to the current workstation, then finds the job with the highest priority number according to the active dispatching rule, and lastly puts this job in the first position in its queue. The DSS is tested under low, normal, and high demand rate scenarios with respect to six performance criteria. It is observed that the DSS improves the system performance by increasing workstation utilization and decreasing both the number of tardy jobs and the amount of waiting time regardless of the employed dispatching rule.
\end{abstract}

Keywords: industry 4.0; dynamic job-shop scheduling; simulation; decision support systems; internet of things

\section{Introduction}

Production is the transformation of natural resources to value-added products or services to meet consumer needs. In order to manage the production well, it is necessary to meet the consumer demands in terms of price, time, quantity, and quality, while decreasing the inventory levels and increasing the stock cycle speed/service level. At this point, questions such as which product, how many, which features, where, and by whom, should be answered to minimize production costs or maximize profits of an organization.

In a job-shop production environment, production is mostly carried out according to the customer order, the due date of which is usually set by the customer. Since the variety of products is high and the order size is low, production flows (routes) usual change from product to product among universal machines in the workshop. Therefore, the coordination of production resources in a job-shop production environment is often difficult. This challenge necessitates the use of advanced production planning and control systems in job-shop environments. 
Scheduling is the planning of the activities in the job-shop at the operational level (day, hour, minute, etc.). When scheduling production, various performance criteria should be considered, such as (i) timely delivery (minimization of delays), (ii) reduced time spent in the system (minimization of waitin), and (iii) maximization of machine utilization rates [1].

In a job-shop, scheduling of jobs is usually performed with static dispatching rules. This scheduling approach is ineffective because it does not consider dynamic factors like new arriving orders and probabilistic or stochastic real-life problems such as job postponement or machine failures [2]. Moreover, research shows that classical scheduling fails to meet the needs of production environments in practice $[3,4]$. Thus, advanced scheduling tools are needed to model this dynamic production environment.

One of the tools to deal with such a dynamic production environment is simulation. Simulation allows modeling and analysis of real-life processes and systems in a computer environment in shorter times with lower costs [5-7].

This study proposes a decision support system (DSS) designed to increase the performance of dispatching rules in dynamic scheduling using real-time data, hence to increase the overall performance of the job-shop. To analyze its effects, it is run with popular dispatching rules selected from the literature on a simulation model created in Arena ${ }^{\circledR}$. When the number of jobs waiting in the queue of any workstation in the job-shop falls to a critical value, the DSS can change the order of schedules in its preceding workstations to feed the workstation as soon as possible. For this purpose, it first determines the jobs in the preceding workstations to be sent to the current workstation, then finds the job with the highest priority number according to the active dispatching rule, and lastly puts this job at the first position in its queue.

The data needed for the DSS includes real-time machine and product status including operating conditions, workstation queue status, workload, etc. The data is collected from production tools that are capable of communicating with each other via the Internet of Things (IoT). The IoT is the network of devices such as vehicles and home appliances that contain electronics, software, sensors, actuators, and connectivity that allows these things to connect, interact, and exchange data. It involves technologies such as Wi-Fi, Bluetooth, and Radio Frequency Identification (RFID). The functioning of a representative job-shop equipped with the IoT technologies is shown in Figure 1. In manufacturing shop floors, use of the IoT has turned machines into smart manufacturing objects that can communicate with each other, enabling access to vast amounts of real data [8]. In manufacturing, IoT could generate so much business value that it is believed to lead to the Fourth Industrial Revolution, which is also referred to as Industry 4.0.

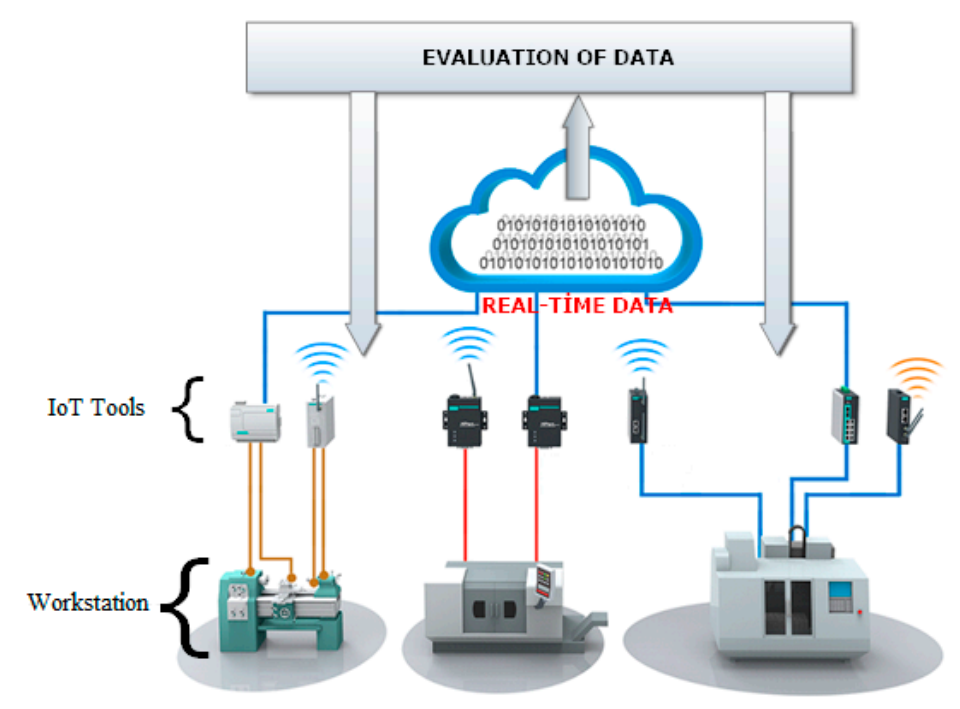

Figure 1. Functioning of the system. 
This system can be integrated into an Enterprise Resource Planning (ERP) information system to make scheduling more effective. We believe that improving the efficiency of production management activities with such approaches could lead to an increase in the demand for Industry 4.0 practices.

Before introducing the functioning of the proposed system in Section 4, a literature review and discussion on dispatching rules are presented in Sections 2 and 3, respectively. Later in Section 4, both the designed system and the developed simulation model are discussed. Finally, conclusions and future work are supplied in Section 5.

\section{Related Work}

In this section, we presented approaches and methods used to determine dispatching rules in different production environments.

Marinho et al. [9] developed a decision support system for a dynamic production scheduling system. They stated that these systems are suitable for small and medium enterprises. In this study, the manufacturing orders are scheduled dynamically. The scheduling was carried out with an earliest/latest finish, minimum/maximum slack, smallest free intervals, and minimum delay heuristics. Deadlines of manufacturing orders and resources occupation were considered in the study. In addition, an interface was developed in the study for helping managers make faster decisions.

Aydin and Oztemel [10] developed an approach for the solution of the dynamic job-shop type scheduling problem by using the agent and the simulated environment. The intelligent agent determines the most appropriate rule in the real time production environment, whereas scheduling is carried out using the rule chosen by the simulation technique. The intelligent agent used in the model is trained with a learning algorithm developed in the study. The results obtained with the developed smart agent are better than shortest processing time (SPT), cost over time (COVERT), and critical ratio (CR) rules.

Li et al. [11], studied on a real time production improvement through bottleneck control. They stated that a dynamic bottleneck control system is developed in order to efficiently use the finite manufacturing resources. Their objective was to achieve a continuous production improvement. The method they developed is applied in an automotive assembly line. As a result, they reduced the downtime of the bottleneck machine.

Heilala et al. [12] developed a simulation-based decision support system as an operative simulation model that enables to handle unforeseen events such as downtime and changes in operations. In their study, they stated that a simulation-based decision support system could be used to help achieve more efficient manufacturing. They discussed that data integration, automated simulation, and the visualization of results in this field.

Mahdavi and Shirazi [13] presented a review of intelligent decision support systems in production planning of flexible manufacturing systems. In their study, they developed real time control of the shop floor. They presented performance criteria for effective and efficient control of the production. They determined the sequence of the jobs in the system using the developed rules.

Sharma and Jain [14] examined the dynamic job-shop type scheduling problem in the stochastic environments by adding the time-dependent preparation times constraint. In the study, makespan, average flow time, maximum flow time, average tardiness, maximum tardiness, number of tardy jobs, total setup time, and average setup time were calculated by the developed algorithm. The JMEDD rule developed in the study gave the best value among all rules. In another study, Sharma and Jain [15] developed four new rules for the same problem that was considered by them. These rules are: (1) TDDSSPT: Shortest (time to due date + setup time + processing time); (2) JTDDSSPT: Same setup time and shortest (time to due date + setup time + processing time); (3) JSLACK: Same setup time and shortest slack time; and (4) JSLACKW: Same setup time and the shortest slack time per unit job.

Different from other works, Zhong et al. [16] used data that is obtained from a production environment using the Radio Frequency Identification (RFID) system. This system collected data and analyzed these data with data mining to determine standard processing times and dispatching rules. 
Next, decision trees were used to find that the use of concurrent data improves the determination of dispatching rules.

Kulkarni and Venkatesvaran [17] developed the simulation-based optimization algorithm (SbO) for job-shop type scheduling problems. They developed a hybrid algorithm to solve the problem. The developed algorithm has been tested in deterministic and stochastic environments. Obtained results were better than classical mixed integer programming model.

Zhong et al. [8] carried out a Big Data Analytics for RFID logistics data by defining different behaviors of smart manufacturing objects. They developed physical internet-enabled intelligent shop floor. The task weight was considered in the logistics decision-making. According to results of the application, the highest residence time occurs in a buffer with the value of $40.57 \%$ of the total delivery time.

Phanden and Jain [18] developed a genetic algorithm approach that is based on a simulation model. In their study, the model selects a job that becomes a candidate to change the available process plans. The objective of the model is to minimize mean tardiness. Three case studies were conducted in their study. They found that changing the current plan according to algorithm results helped to reduce mean tardiness.

Kuck et al. [19] proposed a data-driven simulation-based optimization algorithm for the control of dynamic production systems. In the present study, it was emphasized that flexibility in production is very important. They have developed an approach for the re-scheduling of production according to the new situations considering factors that may cause confusion, such as the simultaneous arrival of a large amount of orders.

Ersoz et al. [20] tried to reduce the difference between practice and scheduling theory. They adapted the real-time information generated by the process control and control systems, to their planning activities. In the offered system, the dynamic structure of the production environment is immediately perceived and the schedule is updated according to the new conditions. The traceability of the parts increased in the factory. In addition, unnecessary waiting or downtimes have been minimized.

Zhang et al. [21] studied real time job-shop scheduling. In their study, they offered two algorithms: the simulation-based value iteration and simulation based $Q$ learning, which were developed to solve the scheduling problem from the perspective of a Markov decision process (MDP). They also used an intelligent system to estimate value function. The MDP rule is compared with SPT, longest processing time (LPT), first-in-first-out (FIFO), and CR. It is observed that MDP performed better than others.

Bierwirth and Kuhpfahl [22] proposed a new approach by synthesizing the GRASP algorithm with local search methods that minimized the total weighted tardiness in job-shop type scheduling. The model based on critical tree building produced better results in terms of total processing time criterion compared to the conventional GRASP algorithm.

Xiong et al. [23] proposed a simulation-based model for determining dispatching rules in a dynamic scheduling problem where job release times and extended technical priority constraints are included. The proposed algorithm reduced the total tardiness and the number of tardy jobs.

Zhang et al. [24] reviewed the literature on job-shop scheduling problems and discussed new perspectives under Industry 4.0. They reviewed more than 120 papers. They stated that under Industry 4.0, the scheduling problems are dealt with new methods and approaches. According to their findings, scheduling research needs to shift its focus to smart distributed scheduling modeling and optimization. According their evaluation, this can be achieved with two approaches: (1) combining traditional methods and proposing a new method and (2) proposing new algorithms for smart distributed scheduling.

Rossit et al. [25] described the concept of intelligent production that emerged with Industry 4.0 in their work. They have dealt with the issue of smart scheduling, which they believe to have an important place in today's production understanding. They have developed the concept of tolerant scheduling in a dynamic environment in order to prevent the need for re-scheduling in production. Similarly, Tao et al. [26] stated that one of the important studies conducted in the literature in the 
scope of Industry 4.0 is dynamic scheduling. They examined the recent innovations in production systems and the smart manufacturing approaches, as well as models that came up with Industry 4.0. In the study, the analysis of the data life cycle in production and the use of large data in production are explained. Conceptual models on the use of large data in production is developed and the use of large data for different sectors is explained with examples.

Jiang et al. [27] studied an energy-efficient job-shop scheduling problem. Their aim was to minimize the sum of the energy consumption cost and the completion-time cost. However, the handled problem was considered NP-Hard. Thus, they developed an improved whale optimization algorithm for solving this problem. They used dispatching rules, nonlinear convergence factors, and mutation operation for the improvement of whale optimization algorithm. To show the effectiveness of the algorithm, they performed simulations. According to results of simulations carried out, the algorithm provided advantages in terms of efficiency.

Ortiz et al. [28] analyzed a flexible job-shop problem and proposed a new model for the solution. They formulated a real-world production-scheduling problem and also provided an efficient tool to solve it. They developed a new algorithm that minimizes average tardiness and found better solutions than the existing dispatching rules.

Ding and Jiang [29] discussed the effect of the IoT technology in a manufacturing environment. They state that, with IoT, production data increased but that these data are sometimes discrete, uncorrelated, and hard-to-use. Therefore, they developed a method to use invaluable data. They provided an RFID-based production data analysis method for production control in IoT-enabled smart job-shops. In addition, a big data approach was developed to excavate hidden information and knowledge from the historical production data.

Leusin et al. [30] developed a multi agent system in a cyber-physical system to solve the dynamic job-shop scheduling problem. The proposed solution had self-configuring features in the production line. This was achieved with the use of agents and IoT. Real time data were used for efficient decision making in the job-shop. The model was tested with a real case study. Under different scenarios, they gained results that are more efficient than standard dispatching rules. In addition, the advantages of using dynamic data and IoT in industrial applications are discussed.

Zhang et al. [31] emphasized the importance of learn concepts in operational management, especially the importance of the lean approach in Industry 4.0. In this study, process control theory was used for lean methods. Thus, they proposed Lean-Oriented Optimum-State Control Theory (L-OSCT) in the study. L-OSCT provides dynamic process control in industrial networking systems. The application was carried out in a large-size paint making company to show the effectiveness of the approach.

After examining the relevant literature, it was observed that several models were developed to determine dispatching rules in dynamic job-shop type scheduling. As a contribution, we developed a decision support system for dynamic environments that could work with different dispatching rules. Our aim was to increase the efficiency of the production management and job-shop.

\section{Dispatching Rules in Scheduling}

Scheduling aims to assign jobs to workstations according to a dispatching rule was done to determine order of processing. These rules are procedures designed to provide good solutions to complex problems in a real-time production environment [4]. Many researchers have proposed various dispatching rules to optimize some performance criteria in a production environment. Since the list of orders to process is updated continuously, the actual problem is dynamic and complex; however, many classical rules do not take this dynamic nature into account. By taking advantage of the modern information technology provided in Industry 4.0, dispatching rules that could handle this dynamic and complex structure could be developed. However, it should be noted that a dispatching rule could not improve all performance criteria at the same time. 
When scheduling the jobs according to a specific rule (as described below), a priority value is calculated for each job in the queue. Later, the job with the smallest or the largest value is selected and assigned to the workstation.

Dispatching rules can be classified in various ways. The rules which are assigned according to the conditions in the workshop can be grouped under three major classes as given in Figure 2.

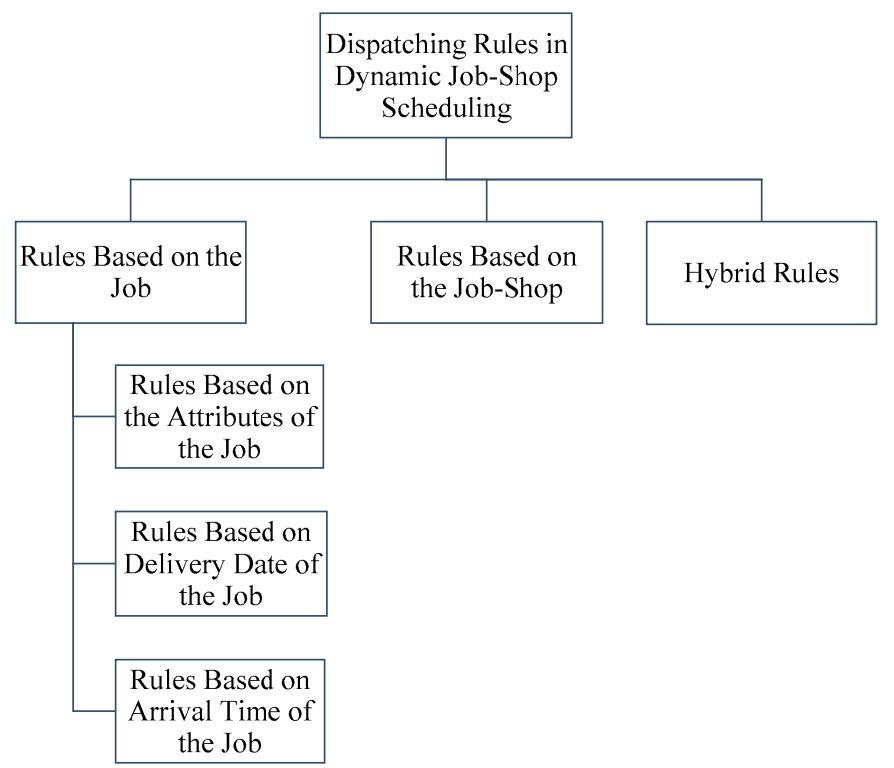

Figure 2. Dispatching rules in job-shop scheduling.

Rules Based on the Job: According to the dispatching rules based on the job, the assignment is done by ignoring the interdependencies between the workstations. Priorities for jobs are determined with respect to some of the attributes and values of the job, such as arrival times, processing times, due dates, etc. Then, the job having the smallest priority value is selected first. Rules such as SPT, EDD, SLACK, and PR can be classified as rules based on the Job.

Rules Based on the Job-Shop: In order to increase the efficiency in smart factories of the future, the components and subsystems must be integrated with each other. For this integration, machines should work intelligently by communicating with other machines. In such a system, process monitoring can be carried out in a comprehensive and effective manner using simultaneous data from the machines and other units. The machines will be able to plan their own production resources. Thus, lean manufacturing and just-in-time manufacturing could be realized.

Until recently, real-time data to show the status of the job-shop were not available. Therefore, dispatching rules that can update the priority values of the jobs dynamically and autonomously were not very common. Work load in next queue (WinQ) rule is a good example for this new class of rules.

Hybrid Rules: Hybrid rules are formed by combining two or more dispatching rules. In this case, a priority value is calculated based on the priority values of these rules. This value is used to specify the job to be assigned.

\section{Dispatching Rules Considered in the Study}

The DSS moves in whenever the number of jobs waiting in the queue of any workstation in the job-shop falls to the critical value of one. The DSS is designed to increase the performance of dispatching rules in dynamic scheduling using real time data. For this purpose, five dispatching rules with good job-shop performances, which were demonstrated in the literature, are selected in order to compare the performances of the dispatching rules with and without the DSS.

These rules are explained in this section. Notations are given in Table 1. 
Table 1. Notations for Dispatching Rules.

\begin{tabular}{llcl}
\hline$\pi_{i, j}$ & Priority value in the jth operation of job & $n_{i}$ & Total number of operations of job \\
\hline $\mathrm{d}_{\mathrm{i}}$ & Due date of job & $\mathrm{A}_{\mathrm{i}}$ & Arrival time of job \\
\hline $\mathrm{P}_{\mathrm{i}, \mathrm{j}}$ & Processing time of the jth operation of job & $\mathrm{t}$ & $\begin{array}{l}\text { The time when a dispatching } \\
\text { decision is needed }\end{array}$ \\
\hline
\end{tabular}

i: Job Index; j: Operation Index; k: Current Operation Step.

Smallest Processing Time (SPT): In this rule, the priority value is the processing time at the workstation. Between the jobs waiting in the queue, the job with the smallest processing time in the queue is selected as the job to be processed first.

$$
\pi_{\mathrm{i}, \mathrm{k}}=\mathrm{P}_{\mathrm{i}, \mathrm{k}}
$$

Earliest Due Date (EDD): In this rule, the priority value of jobs is the due date. Between the jobs waiting in the queue, the job with the earliest due date in the queue is selected as the job to be processed first.

$$
\pi_{\mathrm{i}, \mathrm{k}}=\mathrm{d}_{\mathrm{i}}
$$

Shortest Slack Time (SLACK): In this rule, the priority value is obtained by subtracting the remaining total processing time from the remaining time to due date. Between the jobs waiting in the queue, the job with the smallest priority value in the queue is selected as the job to be processed first.

$$
\pi_{\mathrm{i}, \mathrm{k}}=\mathrm{d}_{\mathrm{i}}-\left[\mathrm{t}+\sum_{\mathrm{j}=\mathrm{k}}^{\mathrm{n}_{\mathrm{i}}} \mathrm{P}_{\mathrm{i}, \mathrm{j}}\right],
$$

Priority Ratio (PR): In this rule, the priority value is obtained by dividing the remaining time until the due date by the remaining total processing time. Between the jobs waiting in the queue, the job with the smallest priority value in the queue is selected as the job to be processed first.

$$
\pi_{\mathrm{i}, \mathrm{k}}=\left(\mathrm{d}_{\mathrm{i}}-t\right) / \sum_{\mathrm{j}=\mathrm{k}}^{\mathrm{n}_{\mathrm{i}}} \mathrm{P}_{\mathrm{i}, \mathrm{j}},
$$

Work load in the next Queue (WinQ): Apart from these static dispatching rules, a dispatching rule that can be adapted to dynamic environments is presented below. The rule WinQ was proposed by Holthaus and Rajendran [32]. This rule determines the priority value of a job by considering the conditions of the job-shop. In this rule, priority value is obtained by looking at total processing times of all jobs in the next workstation, depending on a job's route. Among the jobs waiting in the current queue, the job with the smallest priority value is selected as the next job to be processed. They reported that use of this rule minimizes the average flow time. In cases when the utilization of a job-shop is high, the due dates are determined in A narrow range. This rule also minimizes the tardiness of the jobs and the ratio of the tardy jobs.

\section{Decision Support System}

A DSS is a computerized information system used to support decision-making in an organization. The DSS proposed in this study can be considered as an automated DSS [33], which automatically collects data from the job-shop, analyze the data, and intervenes in the processing order of the jobs if necessary. In other words, it continuously monitors operations, seeks opportunities to increase the job-shop performance, and formulates a better processing order and implements it.

When dispatching rules are used for scheduling, the rule to be applied is determined before the system starts running and no modification are allowed at any time. In this study, we propose a new 
dynamic approach where priority of the jobs can be updated in real time depending on the information on the current status of the workstations. The goal is to improve the performance of the system by decreasing idle time in the workstations.

To collect real-time data from the workstations, the status of the machines (idle, busy), queue lengths, and the property of the jobs in the queue (remaining processing time, processing time, due date etc.) are sent to the management module of the system. When the information is received by the DSS, the system makes necessary modifications in the queue order if it is needed. As soon as the number of jobs waiting in a queue at any workstation falls to a critical level (in this study this critical level is chosen as one), the DSS examines all the preceding workstations to detect the jobs that will be sent to this workstation. Then, it determines the job with the highest priority number according to the active dispatching rule. Finally, the DSS places this job to the first order of the its queue so that it will be first one to be processed when the station becomes idle. Thus, idle times will be avoided in the workstations as much as possible.

To explain how this approach works, an example is presented in Figure 3.

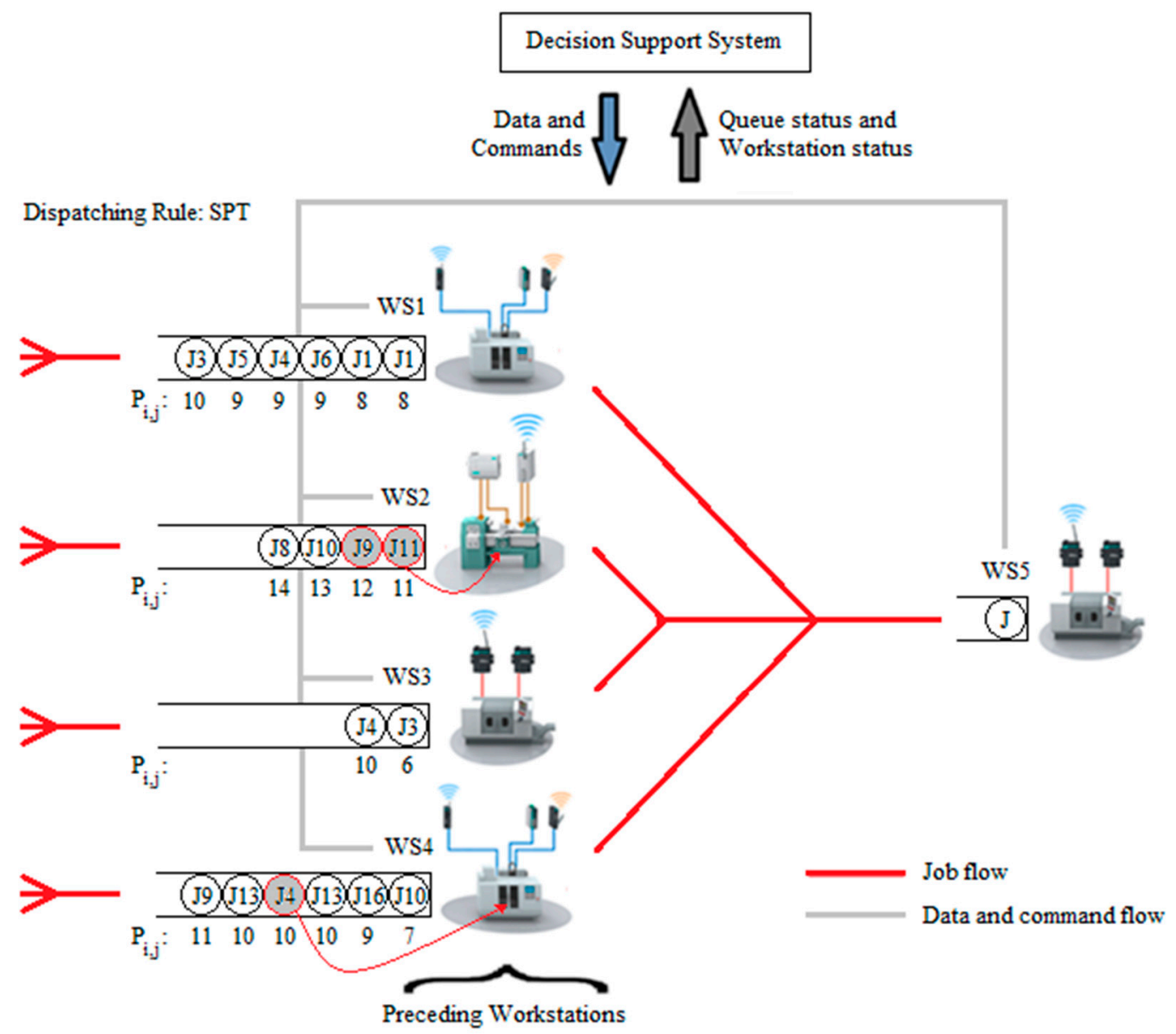

Figure 3. An example of how a Decision Support System (DSS) works.

In this example, suppose that at a specific time point, Figure 3 illustrates the current queue order in the system. Further, suppose that the DSS works under the SPT rule to schedule the jobs in the system and the number of jobs in the queue of WS5 drops to one (a critical level). When the route information is examined, it is determined that WS1, WS2, WS3, and WS4 are the preceding workstations that could send the jobs either to WS5 or to other workstations, depending on the route of the jobs. Jobs that could be processed in the preceding workstations of WS5 are given below: 


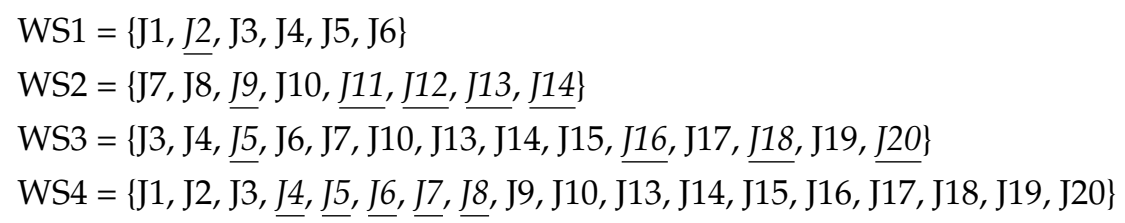

The jobs that are underlined in the lists are the ones that will be sent to WS5 after processed in their current workstations. The other jobs will be sent to other workstations according to their routes. The routes and precedence orders can be seen in Table 2 in the Section 5.

The DSS first determines which of these jobs could be processed next in WS5 by checking WS1, WS2, WS3, and WS4. The job numbers colored in gray in each queue in Figure 3 are the jobs that could be processed in WS5, namely J4, J9, and J11. Among them, J4 is selected since it has the smallest processing time (according to SPT). This job is in the WS4 queue, and hence will be processed in the WS4 as soon as it becomes idle.

Table 2. Routes and Unit Processing Times of Parts.

\begin{tabular}{|c|c|c|c|c|c|c|c|}
\hline & Operation 1 & Operation 2 & Operation 3 & Operation 4 & Operation 5 & Operation 6 & Operation 7 \\
\hline Part 1 & WS1(8) & WS2(12) & WS5(12) & WS4(7) & WS7(13) & & \\
\hline Part 2 & WS1(8) & WS5(19) & WS4(12) & WS8(15) & WS6(10) & & \\
\hline Part 3 & WS1(10) & WS4(8) & WS3(6) & WS6(8) & WS9(9) & & \\
\hline Part 4 & WS1(9) & WS6(10) & WS3(10) & WS4(10) & WS5(14) & WS9(8) & WS10(10) \\
\hline Part 5 & WS1(9) & WS4(10) & WS3(8) & WS5(15) & WS10(11) & WS9(5) & \\
\hline Part 6 & WS1(9) & WS2(10) & WS3(8) & WS4(11) & WS5(10) & WS6(9) & WS10(14) \\
\hline Part 7 & WS2(13) & WS3(11) & WS4(10) & WS5(16) & WS8(18) & WS9(9) & \\
\hline Part 8 & WS2(14) & WS4(14) & WS5(13) & WS7(14) & WS8(18) & WS9(10) & \\
\hline Part 9 & WS2(12) & WS5(9) & WS4(11) & WS7(16) & WS10(14) & & \\
\hline Part 10 & WS2(13) & WS3(9) & WS4(7) & WS8(14) & WS7(14) & WS6(10) & \\
\hline Part 11 & WS2(11) & WS5(10) & WS6(10) & & & & \\
\hline Part 12 & WS2(10) & WS5(11) & WS4(10) & WS8(17) & WS9(12) & & \\
\hline Part 13 & WS2(12) & WS5(12) & WS4(10) & WS3(8) & WS6(8) & WS9(7) & \\
\hline Part 14 & WS2(13) & WS5(10) & WS4(11) & WS3(8) & WS6(9) & WS7(17) & WS10(12) \\
\hline Part 15 & WS3(10) & WS6(9) & WS4(11) & WS8(17) & WS7(15) & & \\
\hline Part 16 & WS3(9) & WS5(10) & WS4(9) & WS7(18) & & & \\
\hline Part 17 & WS3(8) & WS4(7) & WS8(15) & & & & \\
\hline Part 18 & WS3(9) & WS5(10) & WS4(10) & WS6(8) & & & \\
\hline Part 19 & WS3(8) & WS4(9) & WS7(15) & WS6(11) & & & \\
\hline Part 20 & WS3(8) & WS5(11) & WS4(9) & WS8(15) & WS6(12) & & \\
\hline
\end{tabular}

\section{The Simulation Model}

A simulation model for a job-shop production environment, developed in Arena, is used to assess the effects of the proposed DSS. The virtual job-shop environment starts the production with the arrival of a demand for a job. It is assumed that there is a continuous dynamic job demand arrival. Manufacturing takes place at 10 workstations and real-time data can be obtained from them. Each workstation has a different numbers of machines. The representative layout of this job-shop environment is shown in Figure 4.

The purpose of this simulation study is to analyze the effects of introducing the DSS into a job-shop environment that is normally working with some dispatching rule. In this simulation, some real-life phenomena, such machine failures will not be considered since they are not considered to have a significant influence on the performance of the DSS. The simulation model was formed under the following assumptions: 
- $\quad$ Each order has only a single type of job.

- A job cannot be divided and requires different operations in different workstations. For this reason, two operations of the same job cannot be processed at the same time.

- Previous operations of a job must be completed to start a new operation.

- Jobs cannot be cancelled. Each job should be processed until it is completed.

- Machine failures have been ignored.

- Quality control operations are ignored. Thus, waste parts do not occur.

- The time required to move parts between workstations is also ignored.

- Queues in front of workstations are allowed.

- Jobs can wait in a queue for the machine to become idle. On the other hand, machines in workstations can remain idle.

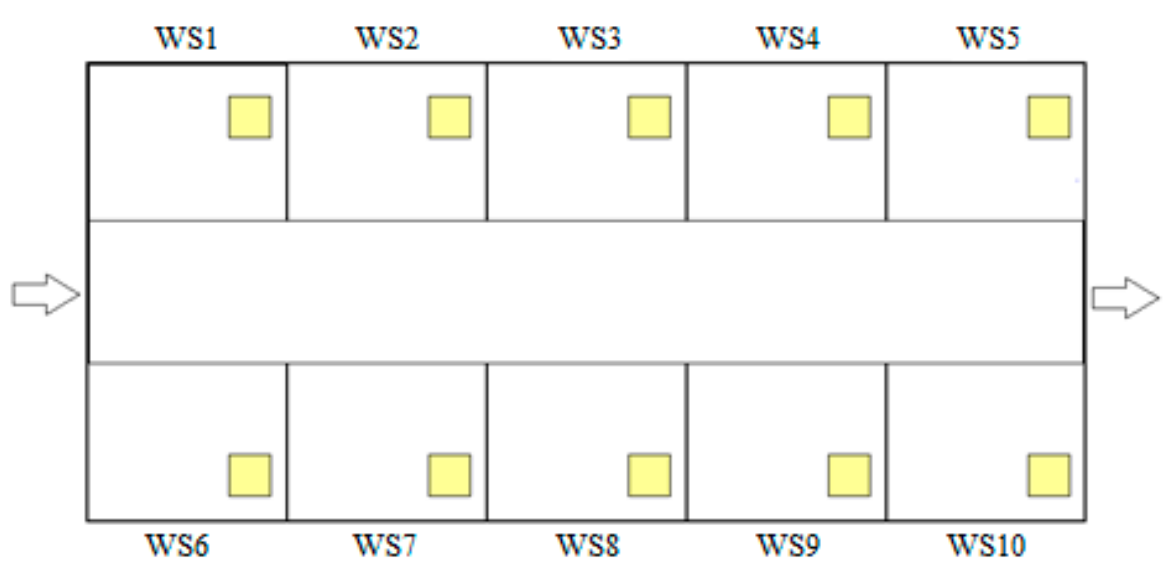

Figure 4. Representative Job-shop Layout Plan.

The routes and the unit processing times of the 20 parts to be produced is obtained from a company that produces spare parts. Data about parts are given in Table 2. It is assumed that the incoming job order can be for any product (each of the 20 parts are equally likely) and the size of the incoming order can be any value between 10 and 30 .

When jobs arrive the system, they are directed to the first workstation on their route. If the targeted workstation is idle, the process starts, otherwise it is kept in the queue. If there are jobs waiting in the queue, a priority value for each job is calculated based on the dispatching rule. Then, the job with the highest or lowest priority is selected. Jobs that are processed in a workstation are directed to their next workstation in their route. The processing of a job is completed when all the workstations on the route are visited.

\subsection{Determining the Best Working Conditions of the System}

The simulation model was set up to represent a job-shop with realistic due dates and a realistic number of machines in workstations, so that job flows are made as smooth as possible without serious bottlenecks.

In order for this setup, the simulation model of the designed system was tested according to the first-in-first-out (FIFO) dispatching rule under exponential job arrival times with various means. The results were compared in terms of the capacity utilization rates of the workstations and the length of the queue formed in front of each workstation (whether the queue lengths increase continuously or cause bottlenecks). It was observed that a mean value of 65 produced satisfactory results. The model was tested with smaller and larger mean values as will be discussed in Section 5.2.

Since some performances criteria are directly related to due dates, due dates were determined as realistically as possible. In real life, due dates are usually set by customers and jobs can have a wide or 
narrow due-date interval depending on how urgent the production is. This must include a coincidence factor that considers the nature of the orders received (normal or urgent) in determining the due date. In our study, a new equation (Equation (5)) was used to determine the due date.

To obtain due dates $\left(\mathrm{d}_{\mathrm{i}}\right)$, the proposed model was again run according to the FIFO dispatching rule and the amount of time spent in the system by each job was found. Next, the processing time of each job was subtracted from the amount of time the job spends in the system to find the waiting time of the job in the system. Then the waiting time was divided to the processing time to obtain a ratio. This ratio shows the percentage of processing time to waiting time. An analysis of these ratios showed that their distribution can be approximated by an exponential distribution except for the fact that it does not start from zero. It is known that exponential distribution can produce values between zero and infinity. Suppose that we obtained zero waiting time from this distribution. This means that the due date of the job would be equal to its arrival time plus its processing time. However, in the job-shop, this due date is not realistic since the job with this due date would probably be a tardy job. To avoid this, we add a constant term $(1+h)$ to the formula presented in Equation (5) to produce more realistic due dates. We defined a tightness factor $h$ to transform the value obtained from the exponential distribution.

Accordingly, the newly proposed due date generation rule (Equation (5)) is as follows;

$$
\mathrm{d}_{\mathrm{i}}=\mathrm{A}_{\mathrm{i}}+\left(\sum_{i=1}^{20} \sum_{j=1}^{10} \mathrm{P}_{\mathrm{i}, \mathrm{j}}\right) \cdot(1+h+\operatorname{Expo}(\mu)),
$$

where $d_{i}$ represents the $i$-th due date and $h$ represents the tightness factor. We determined that $h$ should be 1.5 after trial and error. Below this value, we observed many tardy jobs. Finally, the $\mu$ value is set to 1.5 .

Before testing our scenarios, the simulation model was run by considering different numbers of machines at each workstation to determine the right number of machines at each workstation. Some runs according to different machine combinations $(X, Y$, and $Z$ ) at each workstation were shown in Table 3. Results showed that best machine combination is the Z, with one machine in WS1, WS9, and WS10, three machines in WS4 and WS5, and two machines in the rest of the stations, which were best in terms of average workstation utilization, average waiting time, and average number of parts waiting.

\subsection{Scenarios}

The simulation model was run under three different scenarios:

- Scenario 1: Exponential distribution with a mean of 62 is used to represent arrivals of a fast order rate which overloads the job-shop.

- Scenario 2: Exponential distribution with a mean of 65 is used to represent arrivals of a moderate order rate for a balanced structure.

- Scenario 3: Exponential distribution with a mean of 68 is used to represent arrivals of a slower order rate which causes a more relaxed job-shop.

These three scenarios were run by considering SPT, EDD, SLACK, PR, and WinQ dispatching rules in a job-shop supported by the DSS. Two situations in terms of control are considered: with DSS and without DSS (Normal).

In each scenario, 5000 orders are received randomly according to the arrival speed and a simulation run is completed when all the orders were produced. The fact that the same orders were created at the same time for each scenario enabled one-to-one comparisons. Thus, more realistic evaluations were achieved. 
Table 3. Results of some runs according to different machine combinations.

\begin{tabular}{|c|c|c|c|c|c|c|c|c|c|}
\hline & \multicolumn{3}{|c|}{$X: 1-1-2-2-2-2-2-1-1-1$} & \multicolumn{3}{|c|}{$Y: 1-2-2-3-2-2-2-2-1-1$} & \multicolumn{3}{|c|}{$Z: 1-2-2-3-3-2-2-2-1-1$} \\
\hline & $\begin{array}{l}\text { Average } \\
\text { Number } \\
\text { Waiting }\end{array}$ & $\begin{array}{c}\text { Average } \\
\text { Waiting Time }\end{array}$ & $\begin{array}{c}\text { Average } \\
\text { Workstation } \\
\text { Utilization }\end{array}$ & $\begin{array}{l}\text { Average } \\
\text { Number } \\
\text { Waiting }\end{array}$ & $\begin{array}{c}\text { Average } \\
\text { Waiting Time }\end{array}$ & $\begin{array}{c}\text { Average } \\
\text { Workstation } \\
\text { Utilization }\end{array}$ & $\begin{array}{l}\text { Average } \\
\text { Number } \\
\text { Waiting }\end{array}$ & $\begin{array}{c}\text { Average } \\
\text { Waiting Time }\end{array}$ & $\begin{array}{c}\text { Average } \\
\text { Workstation } \\
\text { Utilization }\end{array}$ \\
\hline WS1 & 0.81 & 344 & 0.42 & 1.13 & 344 & 0.58 & 1.56 & 344 & 0.80 \\
\hline WS2 & 506.64 & 132,869 & 0.92 & 2.34 & 438 & 0.65 & 3.20 & 438 & 0.88 \\
\hline WS3 & 0.55 & 98 & 0.48 & 3.19 & 407 & 0.67 & 6.26 & 582 & 0.92 \\
\hline WS4 & 118.81 & 15,946 & 0.73 & 0.94 & 90 & 0.68 & 3.54 & 248 & 0.94 \\
\hline WS5 & 15.46 & 2638 & 0.71 & 520.83 & 63443 & 0.99 & 3.52 & 313 & 0.91 \\
\hline WS6 & 0.21 & 43 & 0.46 & 0.63 & 94 & 0.64 & 2.78 & 301 & 0.88 \\
\hline WS7 & 0.13 & 42 & 0.44 & 0.40 & 92 & 0.62 & 1.41 & 237 & 0.85 \\
\hline WS8 & 210.25 & 68,121 & 0.99 & 0.65 & 149 & 0.70 & 6.41 & 1081 & 0.96 \\
\hline WS9 & 0.16 & 58 & 0.47 & 0.57 & 148 & 0.66 & 3.03 & 572 & 0.90 \\
\hline WS10 & 0.35 & 172 & 0.49 & 0.58 & 204 & 0.69 & 6.01 & 1548 & 0.94 \\
\hline
\end{tabular}




\subsection{Results of Scenarios}

To reduce the effects of randomness on results, the simulation model was run under 50 replications for each scenario and the averages of performance criteria were obtained.

The scenarios were compared based on the following performance criteria:

- Number of tardy jobs: The timely delivery of orders in the job-shop is of great importance both for customer satisfaction and penalty costs.

- Average waiting time in queue (Avg. waiting time): This criterion attempted to determine whether the waiting periods in the system decreased or not.

- Utilization of the workstations (Avg. utilization): This criterion attempted to determine whether the scenarios increase the efficiency of the system.

- Work in Process (Wip): This criterion attempted to determine whether the scenarios increase the work load within the system.

- Average tardiness (Avg. tardiness): Considering only the number of tardy jobs may lead to incorrect results. It will be better to examine delays together with the average deviations from the due date.

- Average earliness (Avg. earliness): In addition to the late completion of the jobs, it is not desirable to complete jobs early due to inventory holding costs. To avoid these costs jobs should be completed as close as possible to their corresponding due dates.

The simulation results with respect to these performance criteria, are given in the Appendix A. The graphical comparisons of the scenarios based on the criteria are shown in Figures 5-10.

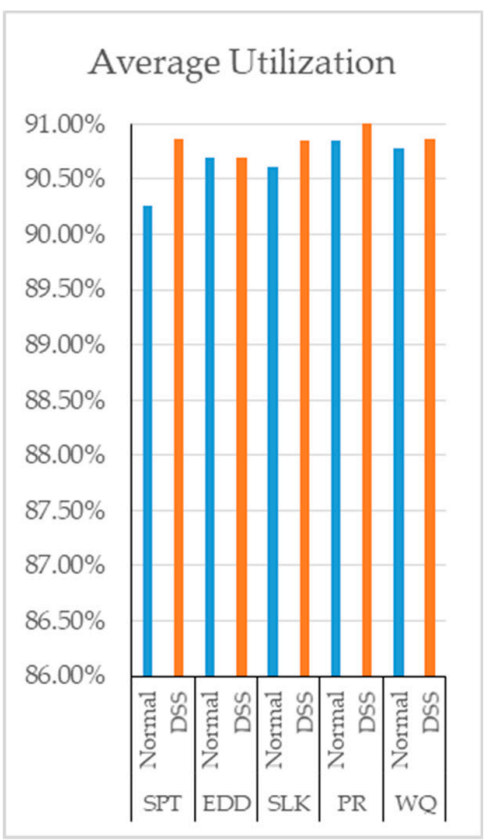

$\operatorname{Expo(62)}$

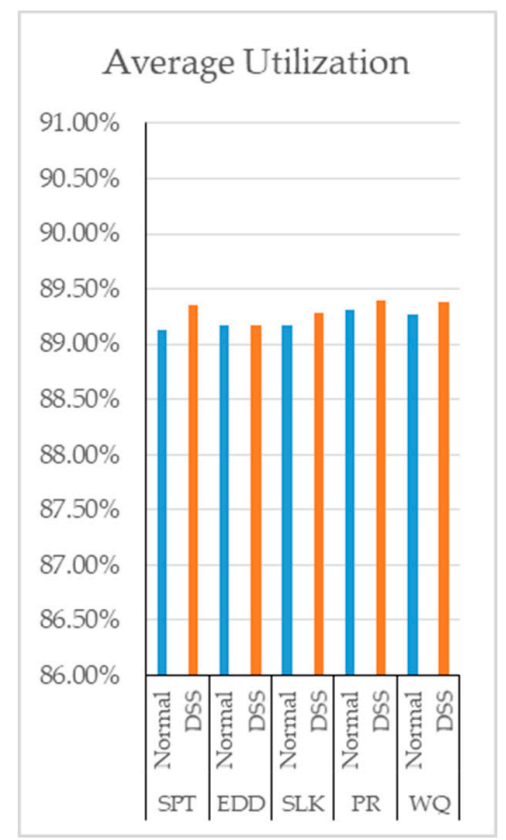

Expo(65)

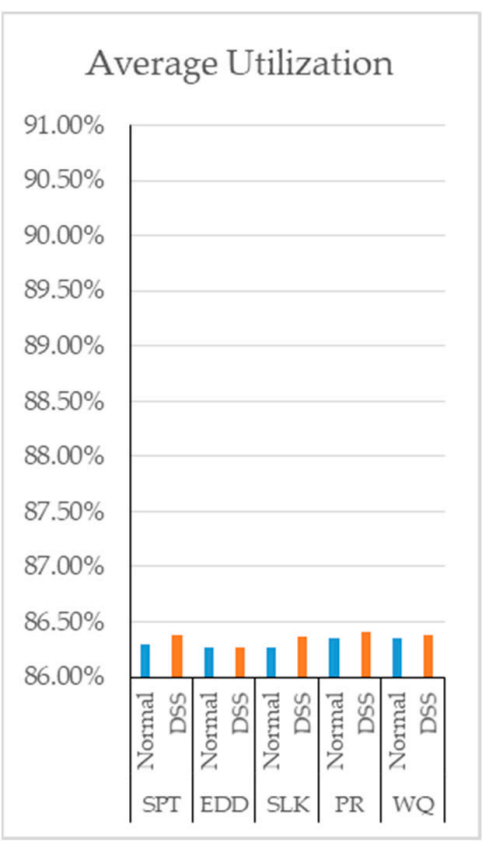

$\operatorname{Expo(68)}$

Figure 5. Average utilization.

Since the DSS basically controls the situation of each workstation and updates the sequence of the jobs according to the dispatching rule, an increase in average utilization of each scenario is observed in Figure 5. 


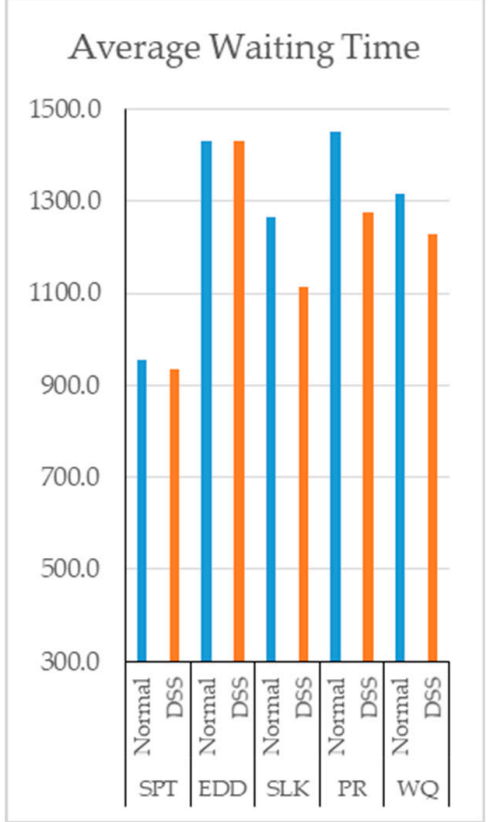

$\operatorname{Expo}(62)$

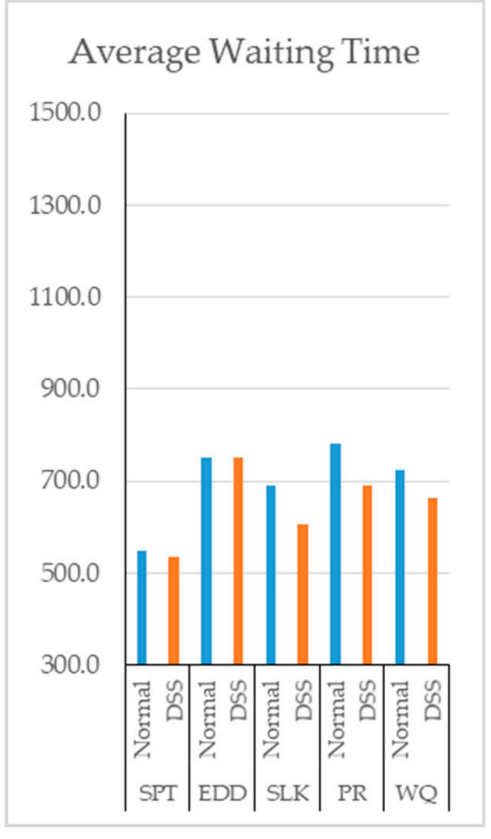

Expo(65)

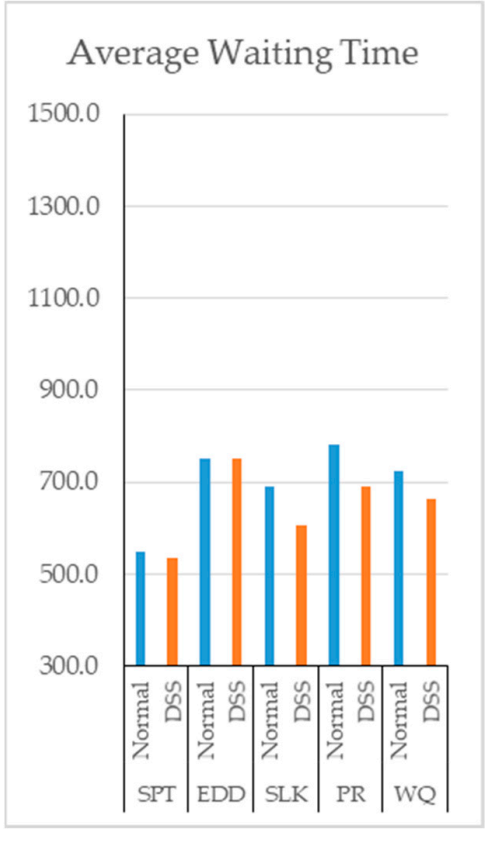

Expo(68)

Figure 6. Average waiting time.

The proposed approach also leads to a decrease on average waiting time of the jobs in the system; this is in line with the increase in utilization rates. On the other hand, the amount of decrease observed in each scenario was different. The sharpest decrease in Figure 6 was observed in Scenario 1.

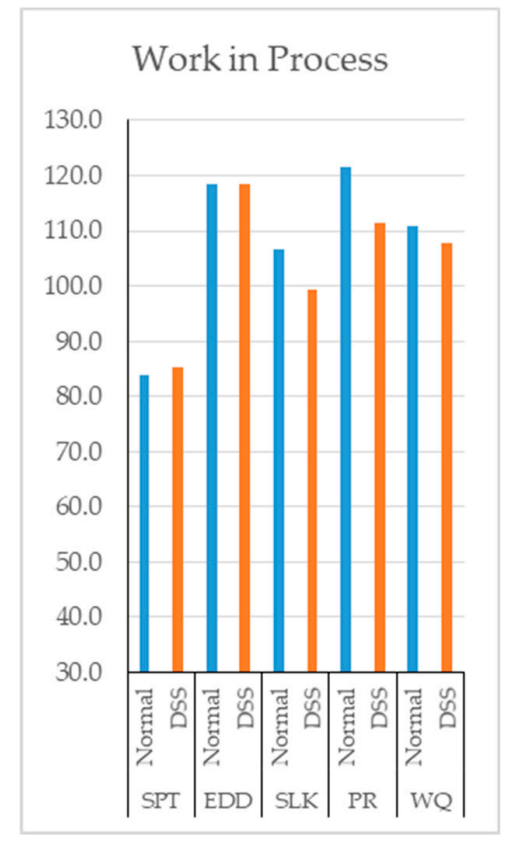

$\operatorname{Expo(62)}$

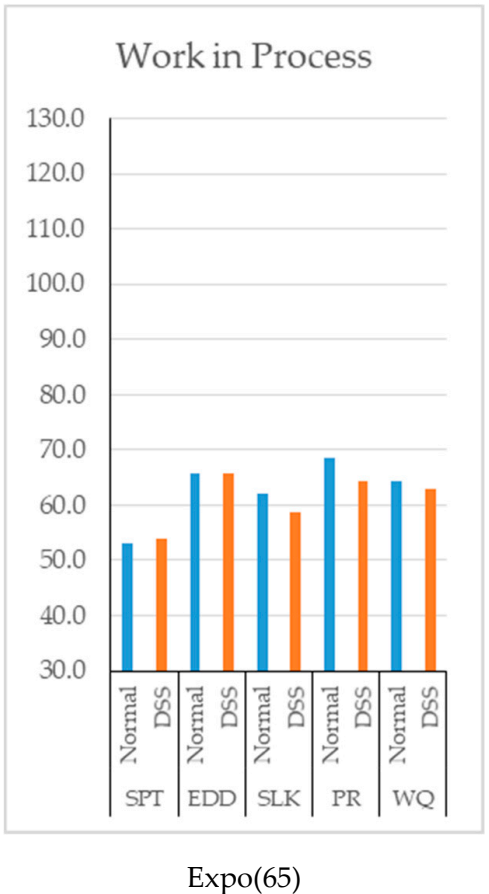

$\operatorname{Expo(65)}$

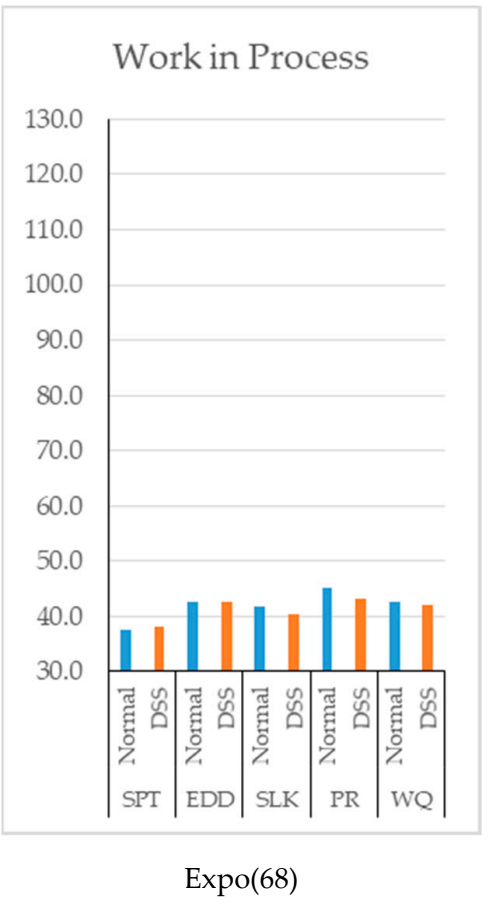

$\operatorname{Expo}(68)$

Figure 7. Work in Process.

Because of the decrease in the average waiting times, the number of jobs in the system decreased except for the cases in which the SPT rule is used. 


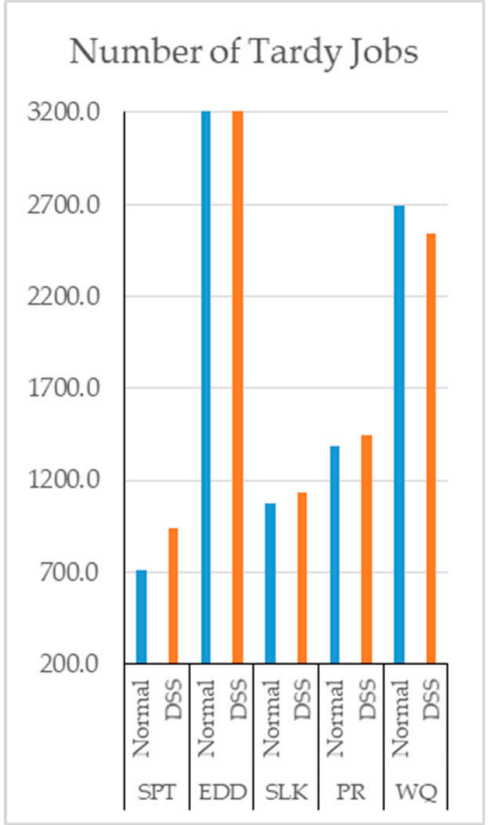

$\operatorname{Expo(62)}$

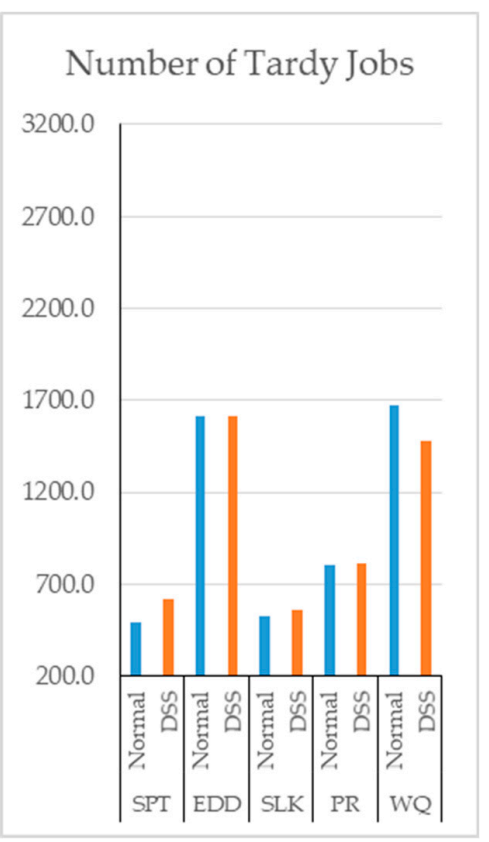

Expo(65)

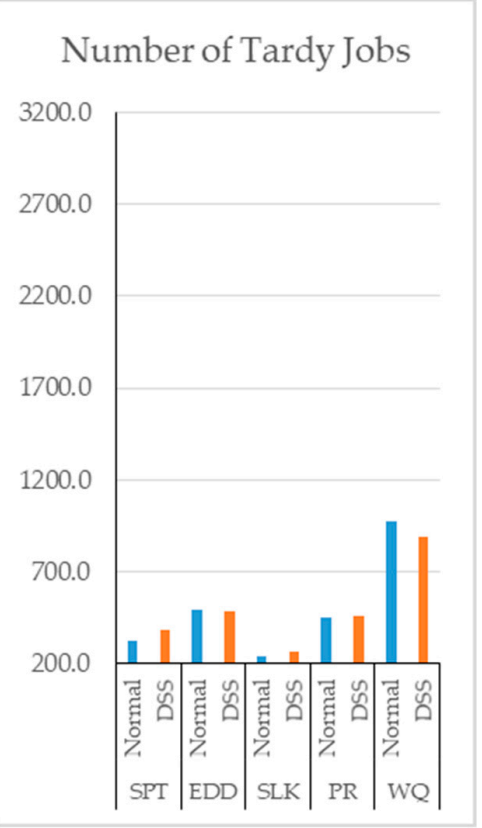

Expo(68)

Figure 8. Number of Tardy Jobs.

After the results presented in Figure 8 were evaluated, we did not observe a significant difference in terms of tardy jobs. This is probably because of the randomness in the due dates and the fact that the EDD, the SLACK, and the PR dispatching rules consider the due dates of jobs. On the other hand, a decrease is observed when the WinQ rule is used since this rule is based on the amount of jobs in the system.

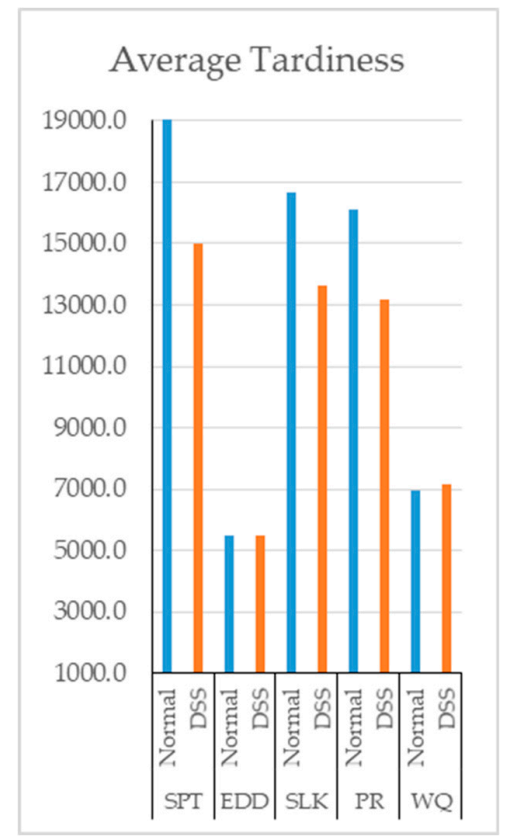

$\operatorname{Expo(62)}$

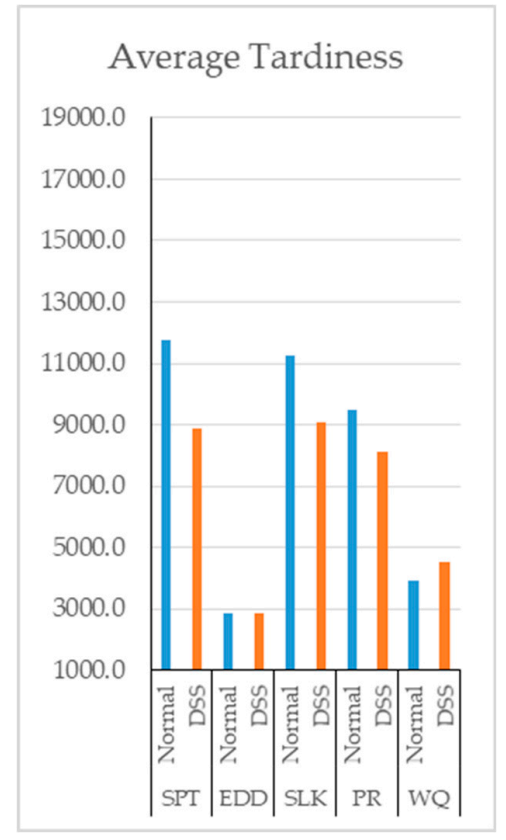

$\operatorname{Expo(65)}$
Average Tardiness

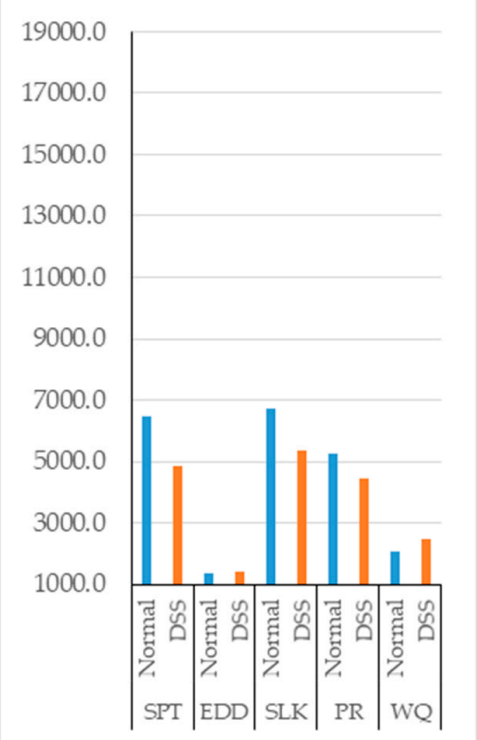

Expo(68)

Figure 9. Average Tardiness. 
A decrease in the number of tardy jobs was not observed when dispatching rules based on due date (see Figure 9). However, for the cases in which WinQ is considered, a decrease in the average waiting times does not occurred because of the increase in the average utilization of workstations.

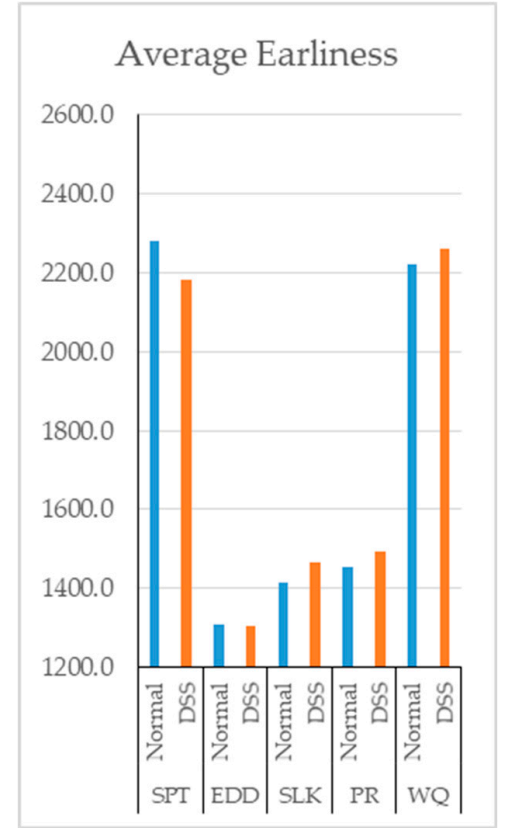

$\operatorname{Expo(62)}$

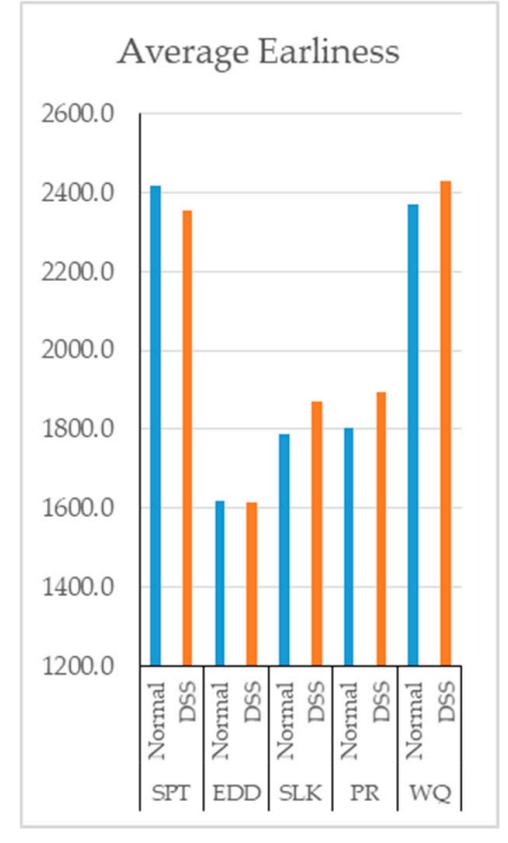

Expo(65)

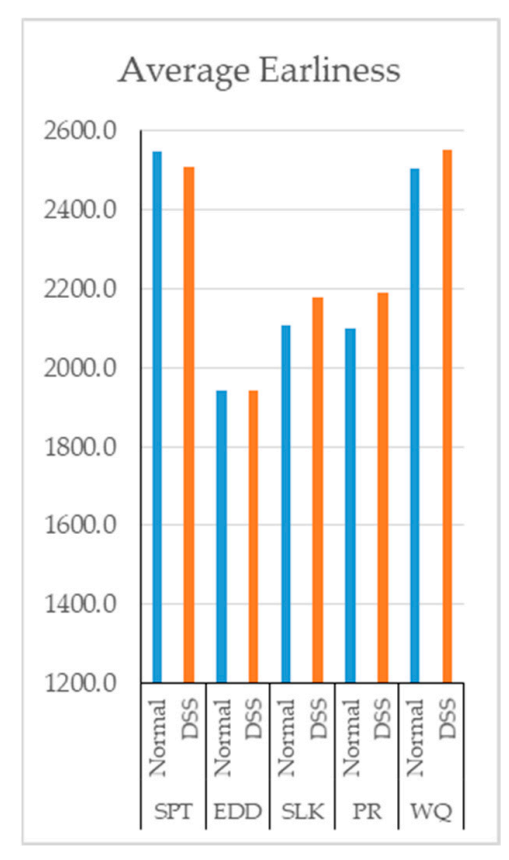

$\operatorname{Expo(68)}$

Figure 10. Average Earliness.

After the results in Figure 10 were examined, an increase in average earliness was observed, except for the case in which SPT rule was used. This was an expected outcome since an increase in utilization and a decrease in waiting times is already observed.

\section{Results and Discussion}

The DSS proposed in this study aims at increasing the performance of dispatching rules in dynamic scheduling using real time data, hence increasing the overall performance of the job-shop. The DSS can work with all dispatching rules. This study shows that a DSS that fed with real time data from a job-shop can help improve several performance criteria. This can be achieved in job-shops equipped with Industry 4.0 hardware and software. The proposed approach improves the performance of a system in terms of number of tardy jobs, average waiting time in queue, average utilization of the workstations, work in process, average tardiness, and earliness as it is discussed in the previous section. As expected, machine utilization increased and thus waiting times in the system and the amount of work-in-process decreased using the DSS.

If the big data collected in real data could be analyzed, inner dynamics between the components of the system could be solved. Understanding the production systems better could help the researchers to develop advanced DSS and the decision makers to make better decisions. Controlling the production environment using real time data, could also help researchers to model the system without making any assumptions. This approach could close the gap between theory and practice and result in realistic solutions. Moreover, it would be possible to validate actual processing times of jobs considering past data about jobs.

Data stored in dynamic databases could also be processed with data mining techniques in order to determine potential problems in the production; to obtain rules that could improve the efficiency of production; to generate rules to effectively control the production; to develop automation based on 
work intelligence; and to improve quality of products and even to design a production management system that could improve itself.

Since the analysis of this big data would help predict the behavior of the system under different conditions, any subsystem could easily integrate into this system. The integration of artificial intelligence or machine learning based subsystems could constitute smart factories of the future. In this respect, this study demonstrates, at a theoretical level, the benefits to be gained by such subsystem integrations, though technological integration in a real job-shop may take substantial time and effort.

\section{Conclusions}

In this study, we considered a dynamic job-shop where job lists are updated dynamically because of continuous arrival of new orders. In future studies, various cases including machine breakdowns, cancellation of orders, and quality control processes should be considered. Handling these more complex cases requires collection of more data with an enriched nature. This will enable the decision makers to control the production better by considering real time management of stochastic disturbances to the system. However, to analyze and evaluate this big data better, advanced decision support systems supported by efficient strategies are needed.

Author Contributions: This paper carried out by all authors equally. Conceptualization, O.O.E. and B.B.; Data curation, A.F.I.; Formal analysis, A.F.I.; Investigation, A.A.; Methodology, A.K.T.; Project administration, G.S.D.; Software, A.K.T.; Supervision, A.A.; Validation, A.F.I., G.S.D., and B.B.; Visualization, O.O.E.

Funding: This research received no external funding.

Conflicts of Interest: The authors declare no conflict of interest.

\section{Appendix A}

\begin{tabular}{|c|c|c|c|c|c|c|c|}
\hline & & SPT & EDD & SLACK & PR & WinQ & \\
\hline \multirow{6}{*}{ 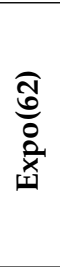 } & Number of tardy jobs & 714.6 & 3333.8 & 1070.9 & 1386.3 & 2693.1 & \multirow{18}{*}{ 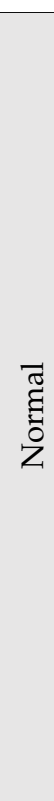 } \\
\hline & Avg. waiting Time & 954.3 & 1430.8 & 1266.7 & 1452.2 & 1317.0 & \\
\hline & Avg. utilization & $90.267 \%$ & $90.701 \%$ & $90.619 \%$ & $90.856 \%$ & $90.786 \%$ & \\
\hline & Work in process & 83.9 & 118.3 & 106.7 & 121.6 & 110.8 & \\
\hline & Avg. tardiness & 20570.1 & 5483.9 & 16681.9 & 16124.5 & 6956.0 & \\
\hline & Avg. earliness time & 2281.4 & 1307.7 & 1416.2 & 1453.0 & 2223.2 & \\
\hline \multirow{6}{*}{ 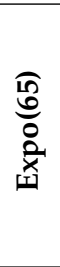 } & Number of tardy jobs & 492.7 & 1614.9 & 525.3 & 802.2 & 1669.2 & \\
\hline & Avg. waiting Time & 548.9 & 750.9 & 690.8 & 782.4 & 723.4 & \\
\hline & Avg. utilization & $89.127 \%$ & $89.171 \%$ & $89.167 \%$ & $89.309 \%$ & $89.270 \%$ & \\
\hline & Work in process & 53.0 & 65.6 & 62.1 & 68.5 & 64.3 & \\
\hline & Avg. tardiness & 11762.6 & 2830.6 & 11249.4 & 9468.0 & 3910.0 & \\
\hline & Avg. earliness time & 2416.6 & 1617.9 & 1785.9 & 1803.3 & 2372.1 & \\
\hline \multirow{6}{*}{ 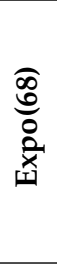 } & Number of tardy jobs & 322.4 & 492.4 & 243.8 & 450.0 & 972.0 & \\
\hline & Avg. waiting Time & 334.9 & 420.9 & 404.4 & 458.1 & 419.3 & \\
\hline & Avg. utilization & $86.291 \%$ & $86.271 \%$ & $86.270 \%$ & $86.353 \%$ & $86.353 \%$ & \\
\hline & Work in process & 37.6 & 42.7 & 41.8 & 45.3 & 42.8 & \\
\hline & Avg. tardiness & 6445.9 & 1361.2 & 6730.3 & 5250.2 & 2065.9 & \\
\hline & Avg. earliness time & 2548.1 & 1942.7 & 2109.5 & 2101.5 & 2504.0 & \\
\hline \multirow{6}{*}{ 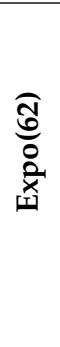 } & Number of tardy jobs & 937.6 & 3333.8 & 1132.6 & 1444.2 & 2542.5 & \\
\hline & Avg. waiting Time & 936.1 & 1430.1 & 1115.3 & 1277.1 & 1230.1 & \\
\hline & Avg. utilization & $90.871 \%$ & $90.703 \%$ & $90.849 \%$ & $91.003 \%$ & $90.864 \%$ & \\
\hline & Work in process & 85.3 & 118.3 & 99.2 & 111.5 & 107.8 & \\
\hline & Avg. tardiness & 14996.8 & 5481.3 & 13636.3 & 13190.4 & 7138.9 & \\
\hline & Avg. earliness time & 2183.4 & 1305.8 & 1465.3 & 1491.7 & 2261.2 & \\
\hline
\end{tabular}




\begin{tabular}{|c|c|c|c|c|c|c|}
\hline \multirow{6}{*}{ 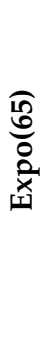 } & Number of tardy jobs & 620.0 & 1612.3 & 556.1 & 811.5 & 1481.2 \\
\hline & Avg. waiting Time & 534.5 & 750.6 & 605.3 & 691.0 & 663.2 \\
\hline & Avg. utilization & $89.356 \%$ & $89.170 \%$ & $89.284 \%$ & $89.402 \%$ & $89.376 \%$ \\
\hline & Work in process & 54.0 & 65.6 & 58.7 & 64.5 & 62.9 \\
\hline & Avg. tardiness & 8863.9 & 2833.7 & 9087.0 & 8112.7 & 4505.2 \\
\hline & Avg. earliness time & 2354.0 & 1615.3 & 1868.9 & 1893.8 & 2429.7 \\
\hline \multirow{6}{*}{ 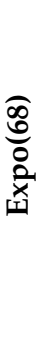 } & Number of tardy jobs & 385.3 & 489.0 & 268.1 & 459.0 & 887.7 \\
\hline & Avg. waiting Time & 317.6 & 420.9 & 357.1 & 400.4 & 381.3 \\
\hline & Avg. utilization & $86.383 \%$ & $86.271 \%$ & $86.359 \%$ & $86.407 \%$ & $86.387 \%$ \\
\hline & Work in process & 38.0 & 42.7 & 40.5 & 43.2 & 42.1 \\
\hline & Avg. tardiness & 4857.4 & 1398.7 & 5368.9 & 4437.0 & 2493.2 \\
\hline & Avg. earliness time & 2509.7 & 1943.3 & 2176.9 & 2192.2 & 2554.3 \\
\hline
\end{tabular}

\section{References}

1. Ersöz, O.Ö.; Türker, A.K. Simultaneous production planning \& control with current workstation loading. Manas J. Soc. Stud. 2016, 5, 5.

2. Elhüseyni, M. Hipotetik Bir Tekstil Atölyesinin Dinamik Çizelgelenmesinde Yollama Kurallarının Benzetim Tekniğiyle Analizi; İstanbul Teknik Üniversitesi, Fen Bilimleri Enstitüsü: Istanbul, Turkey, 2012.

3. Azadeh, A.; Negahban, A.; Moghaddam, M. A hybrid computer simulation-artificial neural network algorithm for optimisation of dispatching rule selection in stochastic job shop scheduling problems. Int. J. Prod. Res. 2012, 50, 551-566. [CrossRef]

4. Larsen, R.; Marco, P. A framework for dynamic rescheduling problems. Int. J. Prod. Res. 2018, 57, 1-18. [CrossRef]

5. $\quad$ Banks, J.; Carson, J.S.; Nelson, B.L.; Nicol, D.M. Discrete-Event System Simulation, 3rd ed.; Printice Hall: Upper Saddle River, NJ, USA, 2001; ISBN 978-0136062127.

6. Law, A.M.; Kelton, W.D. Simulation Modeling and Analysis, 2nd ed.; McGraw-Hill International: New York, NY, USA, 1991; ISBN 978-0073401324.

7. Koruca, H.İ.; Özdemir, G.; Aydemir, E.; Çayırlı, M. Bir simülasyon Yazılımı için Esnek İş Akış Planı Editörü Geliştirilmesi; İşlemlerin Gantt Şemasında Çizelgelenmesi. J. Fac. Eng. Archit. Gazi Univ. 2010, 25, 77-81.

8. Zhong, R.Y.; Chen, C.; Huang, G.Q. Big Data Analytics for Physical Internet-based intelligent manufacturing shop floors. Int. J. Prod. Res. 2015, 55, 2610-2621. [CrossRef]

9. Marinho, R.; Bragança, A.; Ramos, C. Decision Support System for Dynamic Production Scheduling. In Proceedings of the 1999 IEEE International Symposium on Assembly and Task Planning (ISATP'99) (Cat. No. 99TH8470), Porto, Portugal, 24-24 July 1999; pp. 424-429.

10. Aydın, M.E.; Öztemel, E. Dynamic job-shop scheduling using reinforcement learning agents. Robot. Auton. Syst. 2000, 33, 169-178. [CrossRef]

11. Li, L.; Chang, Q.; Ni, J.; Biller, S. Real time production improvement through bottleneck control. Int. J. Prod. Res. 2009, 47, 6145-6158. [CrossRef]

12. Heilala, J.; Montonen, J.; Jarvinen, P.; Kivikunnas, S.; Maantila, M.; Sillanpaa, J.; Jokinen, T. Developing Simulation-Based Decision Support Systems for Customer-driven Manufacturing Operation Planning. In Proceedings of the 2010 Winter Simulation Conference, Baltimore, MD, USA, 5-8 December 2010; pp. 3363-3375.

13. Madhavi, I.; Shirazi, B. A Review of Simulation-based Intelligent Decision Support System Architecture for the Adaptive Control of Flexible Manufacturing Systems. J. Artif. Intell. 2010, 3, 201-219. [CrossRef]

14. Sharma, P.; Jain, A. Analysis of dispatching rules in a stochastic dynamic job shop manufacturing system with sequence-dependent setup times. Front. Mech. Eng. 2014, 9, 380-389. [CrossRef]

15. Sharma, P.; Jain, A. New setup-oriented dispatching rules for a stochastic dynamic job shop manufacturing system with sequence-dependent setup times. Concurr. Eng. Res. Appl. 2016, 24, 58-68. [CrossRef] 
16. Zhong, R.Y.; Huang, G.Q.; Dai, Q.Y.; Zhang, T. Mining SOTs and dispatching rules from RFID-enabled real-time shopfloor production data. J. Intell. Manuf. 2014, 25, 825-843. [CrossRef]

17. Kulkarni, K.; Venkateswaran, J. Hybrid approach using simulation-based optimisation for job shop scheduling problems. J. Simul. 2015, 9, 312-324. [CrossRef]

18. Phanden, R.K.; Jain, A. Assessing the impact of changing available multiple process plans of a job type on mean tardiness in job shop scheduling. Int. J. Adv. Manuf. Technol. 2015, 80, 1521-1545. [CrossRef]

19. Kück, M.; Ehm, J.; Freitag, M.; Frazzon, E.M.; Ricardo, P. A Data-Driven Simulation-Based Optimisation Approach for Adaptive Scheduling and Control of Dynamic Manufacturing Systems. Adv. Mater. Res. 2016, 1140, 449-456. [CrossRef]

20. Ersöz, S.; Türker, A.K.; Aktepe, A. Üretim Süreçlerinin Optimizasyonunda RFID Teknolojisi ve Uzman Sistem Temelli Tümleşik Yapının ERP Sistemine Entegrasyonu ve FNSS Savunma Sistemleri A.Ş.'de Uygulanmasl; San-Tez Project Report; Ankara, Turkey, 2016; Available online: https:/ / adnanaktepe.com/projeler/ (accessed on 14 March 2019).

21. Zhang, T.; Xie, S.; Rose, O. Real-Time Job Shop Scheduling Based on Simulation and Markov Decision Processes. In Proceedings of the 2017 Winter Simulation Conference, Las Vegas, NV, USA, 3-6 December 2017; pp. 3899-3907.

22. Bierwirth, C.; Kuhpfahl, J. Extended GRASP for the job shop scheduling problem with total weighted tardiness objective. Eur. J. Oper. Res. 2017, 261, 835-848. [CrossRef]

23. Xiong, H.; Fan, H.; Jiang, G.; Li, G. A simulation-based study of dispatching rules in a dynamic job shop scheduling problem with batch release and extended technical precedence constraints. Eur. J. Oper. Res. 2017, 257, 13-24. [CrossRef]

24. Zhang, J.; Ding, G.; Zou, Y.; Qin, S.; Fu, J. Review of job shop scheduling research and its new perspectives under Industry 4.0. J. Intell. Manuf. 2017. [CrossRef]

25. Rossit, D.A.; Tohme, F.; Frutos, M. Industry 4.0: Smart Scheduling. Int. J. Prod. Res. 2018, 56. [CrossRef]

26. Tao, F.; Qi, Q.; Liu, A.; Kusiak, A. Data-driven smart manufacturing. J. Manuf. Syst. 2018, 48, 157-168. [CrossRef]

27. Jiang, T.; Zhang, C.; Zhu, H.; Gu, J.; Deng, G. Energy-Efficient Scheduling for a Job Shop Using an Improved Whale Optimization Algorithm. Mathematics 2018, 6, 220. [CrossRef]

28. Ortiz, M.A.; Betancourt, L.E.; Negrete, K.P.; Felice, F.D.; Petrillo, A. Dispatching algorithm for production programming of flexible job-shop systems in the smart factory industry. Ann. Oper. Res. 2018, 264, 409-433. [CrossRef]

29. Ding, K.; Jiang, P. RFID-based production data analysis in an IoT-enabled smart job-shop. IEEE/CAA J. Autom. Sin. 2018, 5, 128-138. [CrossRef]

30. Leusin, M.E.; Frazzon, E.M.; Maldonado, M.U.; Kück, M.; Freitag, M. Solving the Job-Shop Scheduling Problem in the Industry 4.0 Era. Technologies 2018, 6, 107. [CrossRef]

31. Zhang, K.; Qu, T.; Zhou, D.; Thürer, M.; Liu, Y.; Nie, D.; Li, C.; Huang, G.Q. IoT-enabled dynamic lean control mechanism for typical production systems. J. Ambient Intell. Hum. Comput. 2019, 10, 1009-1023. [CrossRef]

32. Holthaus, O.; Rajendran, C. Efficient dispatching rules for scheduling in a job shop. Int. J. Prod. Econ. 1997, 48, 87-105. [CrossRef]

33. Abdullah, M. A Review of Automated Decision Support System. J. Fund. Appl. Sci. 2018, 10, $252-257$.

(C) 2019 by the authors. Licensee MDPI, Basel, Switzerland. This article is an open access article distributed under the terms and conditions of the Creative Commons Attribution (CC BY) license (http://creativecommons.org/licenses/by/4.0/). 